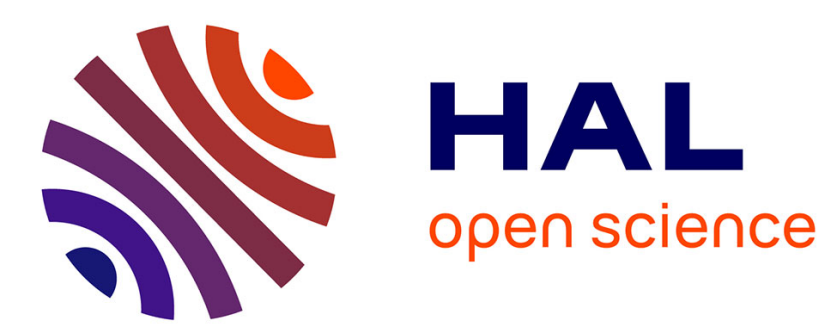

\title{
Pure dissolution kinetics of anhydrite and gypsum in inhibiting aqueous salt solutions
}

\author{
Edgar Alejandro Pachon-Rodriguez, Jean Colombani
}

\section{To cite this version:}

Edgar Alejandro Pachon-Rodriguez, Jean Colombani. Pure dissolution kinetics of anhydrite and gypsum in inhibiting aqueous salt solutions. AIChE Journal, 2013, 59 (5), pp.1622-1626. 10.1002/aic.13922 . hal-03232364

\section{HAL Id: hal-03232364 \\ https://hal.science/hal-03232364}

Submitted on 2 Dec 2021

HAL is a multi-disciplinary open access archive for the deposit and dissemination of scientific research documents, whether they are published or not. The documents may come from teaching and research institutions in France or abroad, or from public or private research centers.
L'archive ouverte pluridisciplinaire HAL, est destinée au dépôt et à la diffusion de documents scientifiques de niveau recherche, publiés ou non, émanant des établissements d'enseignement et de recherche français ou étrangers, des laboratoires publics ou privés. 


\title{
Pure dissolution kinetics of anhydrite and
}

\section{gypsum in inhibiting aqueous salt solutions}

\author{
Edgar Alejandro Pachon-Rodriguez and Jean Colombani ${ }^{1}$ \\ Laboratoire de Physique de la Matière Condensée et Nanostructures; \\ Université de Lyon; Université Claude Bernard Lyon 1; \\ CNRS, UMR 5586; Domaine scientifique de la Doua, F-69622 Villeurbanne cedex, France
}

In the context of the study of the wet creep of plasterboards, we have performed digital holographic interferometry measurements of the dissolution of gypsum of various quarries in water and in aqueous solutions of salts inhibiting dissolution, and of the dissolution of anhydrite in water. This technique is carried out in still water and permits to observe directly the reacting solid-liquid interface. Therefore, contrary to standard bulk measurements, the pure dissolution rate constants, free from any mass transport contribution, have been measured. These rate constants are similar for the cleavage face of the various gypsums. Thanks to their faculty of complexing the surface calcium ions, the investigated phosphate and phosphonate salts inhibit dissolution and reduce the dissolution rate constant of up to more than one order of magnitude. This strong influence may explain their anti-creep role in plasterboards.

Keywords: dissolution, gypsum, anhydrite, holographic interferometry, creep

\section{Introduction}

The knowledge of the dissolution properties of gypsum $\left(\mathrm{CaSO}_{4}, 2 \mathrm{H}_{2} \mathrm{O}\right)$ in aqueous solutions is of primary importance in many situations, among which the weathering of rocks and the gypsum karst formation, ${ }^{1}$ the deformation of natural gypsum rocks, ${ }^{2}$ the quality of drinking water, ${ }^{3}$ the amelioration of soil acidity, ${ }^{4}$ the scale formation in the oil and gas industry, ${ }^{5}$ the measurement of water motion in oceanography, ${ }^{6}$ and the liberation of calcium ions, useful for the geological storage of $\mathrm{CO}_{2}$. These dissolution properties may be considerably modified by the presence of ions in the solution, that adsorb at the surface and hinder the detachment (and attachment) of $\mathrm{Ca}^{2+}$ and $\mathrm{SO}_{4}^{2-}$. Phosphate and phosphonate salts are known to play this role for calcium salts ${ }^{7-9}$ for dissolution as much as for growth, and this complexing faculty is used in the building materials industry to retard the setting of cement, ${ }^{10}$ and

\footnotetext{
${ }^{1}$ Corresponding author, Jean.Colombani@univ-lyon1.fr
} 
in the oil industry or in desalination plants to control scale formation in pipes. ${ }^{11}$ Whereas a consensus about the value of the solubility of gypsum in water exists, ${ }^{5}$ its dissolution rate constant has been debated until recently. ${ }^{12}$ As a consequence, values of its dissolution rate constant in water containing complexing salts just begin to appear. ${ }^{8,9}$

We have proposed recently that the dissolution kinetics of gypsum in water, and the inhibiting role of the above-mentioned salts, is the basic feature for the understanding of the humid creep of plasterboards. ${ }^{13}$ But this statement is still debated and we present here detailed results of dissolution to assert our proposition.

Set plaster is ubiquitous in the building industry, in particular in the form of plasterboards. It is made of intricate gypsum needle-shape microcrystals. Although the link between the microstructure and the mechanical properties of set plaster is still not clear, the assumption of the existence of a nanometric water layer in the majority of the inter-needle bonds has enabled interpretation of the behavior of several properties of the material in presence of water. ${ }^{14,15}$ But this hypothesis was unable to interpret the strong enhancement of the creep of gypsum boards in humid environments. ${ }^{16}$ We have shown that this enhancement originates in the dissolution of gypsum in the intercrystalline water due to the local stresses between the crystallites induced by the applied load. The role of anti-creep additives is therefore to slow down the dissolution of gypsum, which in turn lowers the creep strain rate. ${ }^{13}$ In this context, the knowledge of the dissolution kinetics of gypsum in water containing the anti-creep salts is fundamental, not only to confirm the role of dissolution in humid creep and validate the assumption, but also to find new additives or new processes to fight humid creep.

\section{Diffusion- and convection-free dissolution measurements}

In standard dissolution experiments, the mineral is dissolving in stirred water and the dissolution rate is deduced from the evolution of the bulk concentration in the cell. So overall the dissolution kinetics contains diffusive and convective contributions. Chemical reaction at the interface, Fickian diffusion in the transport boundary layer above the surface, and advection to the measurement device are consecutive events, so the slowest one controls the kinetics of the phenomenon. ${ }^{17}$ For hard minerals like aluminosilicates, dissolution is so slow that it drives the whole kinetics and the mass transport contribution can be neglected. ${ }^{18}$ But for softer minerals like carbonates and sulfates, or for organic compounds, dissolution, diffusion and convection timescales are of the same order of magnitude and their respective contribution can be difficult to distinguish. ${ }^{19}$

In a previous paper, we have collected the dissolution rates of gypsum in water reported in the literature, measured by various techniques (rotating disk, batch dissolution, shaken tube, ... $)^{12}$ We have analyzed the hydrodynamical configuration of each experiment, in order to quantify the diffusive part and remove it from the dissolution rate. This critical analysis of all the literature experiments has yielded the pure dissolution rate constant (also called intrinsic dissolution rate) of gypsum in water, free of any mass transport contribution.

Beside, we have developed an experimental methodology, involving holographic interferometry, that permits a 
direct measurement of this pure dissolution rate constant. ${ }^{20}$ This technique, detailed below, presents two advantages. First the dissolution is studied in quiescent water, necessitating no flow. Therefore no hydrodynamic assumption is needed to compute the pure dissolution rate. Secondly the solid-liquid interface, where the reaction occurs, is directly observed, avoiding thus to have to compute a local quantity (the dissolution rate constant at the interface) from bulk measurements (the concentration in the solution). At first glance, this methodology may appear puzzling, because in the absence of convection, no diffusional boundary layer exists - it can theoretically be defined as infinite. Hence it is not needed to determine wether the phenomenon is transport-controlled or reaction-controlled or mixed to interpret it, both mechanisms being resolved and measured in real-time.

The values deduced from the hydrodynamical analysis of the literature and obtained by holointerferometry agree within experimental error, and recent measurements by channel flow cell are in agreement with this result. ${ }^{8}$ This benchmark value appears to be much smaller than expected by standard methods. In this article, in the context of the study of the humid creep of set plaster, we apply this experimental technique to the measurement of the pure dissolution rate constant of gypsum in water containing various salts, known for their inhibiting effect on dissolution, and of calcium sulfate anhydrite.

\section{Material and methods}

Holographic interferometry is an optical technique usually used, in the case of transparent liquids, for the investigation of diffusion or convection of mass or heat, ${ }^{21}$ that we have adapted for dissolution studies. ${ }^{20}$ During the experiment, the digital hologram, i.e., the three dimensional photograph, of a transparent cell $\left(9.5 \times 10 \times 40 \mathrm{~mm}^{3}\right)$ containing the solution at rest is recorded at time $t_{0}$. Then a piece $\left(\sim 5 \times 5 \times 0.5 \mathrm{~mm}^{3}\right)$ of a gypsum single crystal is deposited at the bottom of the cell. The solid dissolves, the dissolved species diffuse in the cell, so the concentration changes in the fluid. The concentration evolution induces a change of the index of refraction. The two-dimensional map of the difference between the refractive index at times $t$ and $t_{0}$ in the liquid is visualized by interference fringes (Figure 1). In general, interferograms at 30 different times are recorded. From the fringe patterns, the concentration evolution $c(z, t)$ as a function of vertical position $z$ in the cell and time $t$ can be computed (Figure 2). The displacement with time of the curves to the right is the signature of the diffusion of the dissolved species from the bottom to the top of the cell. The displacement with time of the curves upward is a signature of the matter transfer from solid to liquid. Full details about the method can be found in Ref. ${ }^{20}$

An analytical expression of $c(z, t)$ is obtained from solving Fick's equation with the relevant boundary conditions, considering that the dissolution reaction is first order: ${ }^{22}$

$$
c(z, t)=c^{\mathrm{sat}}\left[\operatorname{erfc}\left(\frac{z}{2 \sqrt{D t}}\right)-\exp \left[\frac{k \beta z}{D c^{\mathrm{sat}}}+\left(\frac{k \beta}{D c^{\mathrm{sat}}}\right)^{2} D t\right] \times \operatorname{erfc}\left[\frac{z}{2 \sqrt{D t}}+\frac{k \beta}{D c^{\mathrm{sat}}} \sqrt{D t}\right]\right] .
$$

In this expression, $c^{\text {sat }}$ is the gypsum solubility in the solution, $D$ the diffusion coefficient of the dissolved species 
in the solution, $k$ the dissolution rate constant of gypsum in the solution, $\beta$ the ratio of the reactive surface area and of the cell section surface area, and erfc the complementary error function.

The experimental data are fitted with this theoretical expression with $c^{\text {sat }}, D$ and $k$ as fitting parameters (Figure 2 ). This last coefficient is the thermodynamic parameter linking the dissolution rate $R$ to the distance from chemical equilibrium: $R=s_{\mathrm{r}} k(1-\Omega)$, with $s_{\mathrm{r}}$ the reactive surface area and $\Omega$ the undersaturation in the solution. ${ }^{23}$ This parameter characterizes exclusively the chemical behavior of the solid-liquid interface, whatever the mass transport situation above it. It is directly linked to the Onsager coefficient relating the chemical force and the interfacial matter flux.

Whereas the fit also provides the gypsum solubility $c^{\text {sat }}$ in the additive solution, we have performed independent Induced Coupled Plasma Atomic Emission Spectroscopy measurements. These experiments confirm the holographic values, showing that the gypsum solubility in the additive solutions never departs from its value in pure water (15 mmol L ${ }^{-1}$, i.e., $2 \mathrm{~g} \mathrm{~L}^{-1}$ ), due to the small concentrations of additive that we have investigated.

Although the aim of our work is the study of the influence of inhibiting salts on the gypsum dissolution kinetics, we have also tried to evaluate the influence of the mineral origin on this kinetics. Indeed impurities contained in natural gypsum influence the dissolution velocity, especially close to equilibrium, as evidenced by Jeschke et al. in comparing the behavior of natural and synthetic gypsum samples. ${ }^{1}$ Therefore we have carried out experiments with transparent gypsum single crystals from the quarries of Mazan (Vaucluse, France), Tarascon (Ariège, France), Sig (Mostaganem, Algeria), and provided by MaTeck GmbH. The samples are obtained from the cleavage along the (010) plane of the crystals. No other preparation of the sample is needed, the cleavage providing clean planes, almost atomically flat. ${ }^{24}$ The cleavage is performed just before the introduction of the sample into the optical cell, to avoid atmospheric pollution.

As a matter of comparison, we have also investigated two other types of samples. First we have studied a face found in a natural gypsum sample, the crystallographic direction of which was very close to the (120) plane of the mineral. Secondly we have performed dissolution measurements of the (010) cleavage face of an anhydrite $\left(\mathrm{CaSO}_{4}\right)$ sample from the Tarascon quarry. Being less flat than the gypsum cleavage plane, the investigated face of these samples was polished with silicon carbide papers of grit size down to $15 \mu \mathrm{m}$. The solubility of anhydrite $(24 \mathrm{mmol}$ $\mathrm{L}^{-1}$ ) is larger than the solubility of gypsum. Hence the holographic measurements had to be stopped as soon as the concentration in the cell reached $15 \mathrm{mmol}^{-1}$, gypsum beginning then to precipitate, modifying the concentration field. ${ }^{25}$

The standard deviation and standard error of the measurements $k_{i}$ have been computed by $\sigma=\sum_{i=1}^{N}\left(k_{i}-\bar{k}\right)^{2} / N$ and $\Delta k=\sigma / \sqrt{N-1}$, with $N$ the number of experiments for each sample-solution system, and $\bar{k}$ the average value of the $k_{i}$.

The investigated inhibiting salts are a tartaric acid $\left(\mathrm{C}_{4} \mathrm{H}_{6} \mathrm{O}_{6}\right) /$ boric acid $\left(\mathrm{H}_{3} \mathrm{BO}_{3}\right)$ mixture, Trilon P, i.e., a commercial version of a sodium salt of a polyamino carboxylic acid $\left(\mathrm{C}_{10} \mathrm{H}_{16} \mathrm{~N}_{2} \mathrm{O}_{8}\right.$, CAS no. 454473-50-8), Sequion 
50K33 and Dequest 2054, i.e., two commercial versions of the hexamethylenediamine tetra(methylene phosphonic acid) hexapotassium salt $\left(\mathrm{C}_{10} \mathrm{H}_{22} \mathrm{~K}_{6} \mathrm{~N}_{2} \mathrm{O}_{12} \mathrm{P}_{4}\right.$, CAS no. 38820-59-6), and STMP, i.e., sodium trimetaphosphate $\left(\mathrm{Na}_{3} \mathrm{P}_{3} \mathrm{O}_{9}\right)$. The acid mixture is made of $1 / 6$ of tartaric acid and $5 / 6$ of boric acid in weight. Trilon, Sequion and Dequest contain phosphonate groups. All these additives are known to form complexes with calcium ions and are then expected to adsorb at the gypsum surface and hinder the reaction with water, thus explaining their anti-creep role.

\section{Results and discussion}

The number of experiments performed, average value, standard deviation and standard error of the pure dissolution rate constant in water for the various gypsum samples are collected in Table 1. For the cleavage plane, all values span between 38 and $69 \mu \mathrm{mol} \mathrm{m}{ }^{-2} \mathrm{~s}^{-1}$. Considering the standard errors, this dispersion cannot be viewed as significant. Therefore the natural impurities contained in the crystals are either too scarce to have an impact on the dissolution, or similar in all quarries, having the same influence on all samples, or active only closer to equilibrium than in our experiments. So we have computed an average of the values of $k$ for all the gypsum origins, that can be considered as a reference value for the surface reaction rate constant of the cleavage face of gypsum : $k=(46 \pm 6) \mu$ mol $\mathrm{m}^{-2} \mathrm{~s}^{-1}$. This value is consistent with the one deduced from the analysis of the literature results : $k=70 \mu \mathrm{mol}$ $\mathrm{m}^{-2} \mathrm{~s}^{-1} \cdot{ }^{12}$ The discrepancy between both values should stem from the fact that the literature experiments were usually performed with samples made of compressed powder. Therefore the value deduced from these experiments corresponds to an average of all the crystallographic faces exhibited by the powder grains, whereas ours focusses on one well-defined face.

The value of $k$ of the (120) face of gypsum is slightly higher than the one of the cleavage face, but the large standard error does not enable to state if this discrepancy is significant.

The average value of the dissolution rate constant of anhydrite in water is $k=2.6 \mu \mathrm{mol} \mathrm{m}^{-2} \mathrm{~s}^{-1}$ with $\Delta k=0.3$ $\mu \mathrm{mol} \mathrm{m}{ }^{-2} \mathrm{~s}^{-1}$ for two experiments. Hence anhydrite dissolves more than one order of magnitude slower than gypsum. This was first demonstrated by Jeschke \& Dreybrodt, ${ }^{25}$ who do not provide values of $k$ but report dissolution rates "about two orders of magnitude smaller than those of gypsum measured in the same experimental setup". We note that Mbogoro et al. measure in a channel flow cell a value surprisingly 15 times larger, ${ }^{8}$ close to the value of gypsum. This discrepancy can be tentatively ascribed to the measurement method. The access to $k$ in channel flow cell experiments requires a hydrodynamic modelization of the setup. The model postulates an ideal cell but the real flow field in the channel cannot be observed so the assumptions of the model cannot be checked. In our experiments the interface is directly observed and no hydrodynamical assumption is needed. But discussions about the dissolution measurement methodology are still active ${ }^{19}$ and further experiments are still highly desirable.

Before investigating the role of the various additives, the influence of the concentration of one of them on 
dissolution has been studied. Figure 3 shows the evolution of the dissolution rate constant with the concentration of STMP in the aqueous solution where the (010) plane of Mazan gypsum dissolves. The rate constant is seen to decrease when the concentration increases, reaching a plateau for a concentration of roughly $0.05 \%$. This saturation value of the concentration is very low for such a strong effect, the dissolution rate constant being diminished by more than one order of magnitude, compared to pure water. This derives from the fact that dissolution is a heterogeneous reaction taking place at the solid-liquid interface. As soon as the admixture molecules in the solution have poisoned all the active sites of dissolution of the plane, which are likely to be the kinks in the atomic steps, ${ }^{10}$ the effect is maximal. ${ }^{7}$ For this reason, the experiments were performed for the other additives for a few concentrations higher than $0.1 \%$. Thereby the values of $k$ have always been seen as being independent of the concentration, so the average value has been used.

The number of experiments performed, average value, standard deviation and standard error of the pure dissolution rate constant of the cleavage plane of Mazan gypsum in various aqueous solutions are collected in Table 2. The value for STMP is an average of the values for all the concentrations in Figure 3 larger than $0.05 \%$. Figure 4 is a graphic representation of these results.

The tartaric acid-boric acid mixture induces a slight but significant increase of the dissolution rate constant. We can ascribe this influence to the weak nature of the second dissociation of sulfuric acid. Indeed the fall of the $\mathrm{pH}$ induced by the presence of the tartaric-boric acid leads to the rise of the $\mathrm{HSO}_{4}^{-}$concentration and decrease of the $\mathrm{SO}_{4}^{2-}$ concentration. The dissolution is then expected to accelerate to supply new $\mathrm{SO}_{4}^{2-}$ ions in the solution.

The other additives can be sorted for their increasing inhibiting action: Trilon, Sequion, Dequest, STMP. The hindrance of ion release from the surface by these salts derives from their chelation of the surface calcium ions, inactivating their hydration. It is not possible to discuss the precise mechanism of adsorption from these dissolution measurements alone, but we can infer the strength of this adsorption from the magnitude of the dissolution inhibition. STMP is likely to be the most strongly bound complex with the gypsum surface, due to its ring geometry, favoring tight attachment to the surface ions. This strong ability to block dissolution explains why STMP is an excellent anti-creep admixture of gypsum boards. ${ }^{13}$

We note that our value of $k$ for STMP is 4 times smaller than the one measured by Mbogoro et al. in a channel flow cell. ${ }^{8}$ Again the lower resolution of this methodology can be tentatively ascribed to its indirect nature, with hydrodynamical assumptions needed by its data analysis. The experimental curves exhibiting the concentration as a function of the flow rate are probably not resolved enough to enable to show computationally the changes in the dissolution rate constant that we observed. But further experiments are still necessary to settle this question. 


\section{Conclusions}

In this work, digital holographic interferometry experiments were carried out to study the dissolution properties of gypsum in various inhibiting aqueous solutions. This technique has enabled measurement of the pure surface reaction rate constant of the cleavage face of gypsum of various origins in pure water free from any mass transport effect. All the values are similar and have led to a reference value of the pure dissolution rate constant of the cleavage face (010) of gypsum in pure water. The pure surface reaction rate constant of gypsum has been measured in tartaric acid/boric acid, Trilon, Sequion, Dequest and STMP aqueous solutions. Whereas the first one promotes slightly dissolution, the others inhibit dissolution, the most active one being STMP, for which the dissolution rate contant is lower by more than one order of magnitude than its value in pure water. This inhibiting action is likely to explain the faculty of these salts to limit the humid creep of polycrystalline gypsum materials.

\section{Acknowledgements}

We would like to thank Sylvana Nyd for experimental help, Geert Houvenaghel and Martin Mosquet for fruitful discussions, and Pierre Monchoux and Lucienne Jardin for gypsum and anhydrite samples. This work was supported by Lafarge Centre de Recherche, Région Rhône-Alpes and CNES (french space agency).

\section{References}

1. Jeschke A.A., Vosbeck K., Dreybrodt W.. Surface controlled dissolution rates of gypsum in aqueous solutions exhibit nonlinear dissolution kinetics Geochim. Cosmochim. Acta. 2001;65:27.

2. Hoxha D., Homand F., Auvray C.. Deformation of natural gypsum rock: Mechanisms and questions Eng. Geol.. $2006 ; 86: 1$.

3. Raines M.A., Dewers T.A.. Mixed transport / reaction control of gypsum dissolution kinetics in aqueous solutions and initiation of gypsum karst Chem. Geol.. 1997;140:29.

4. Gobran G.R., Miyamoto S.. Dissolution rate of gypsum in aqueous salt solutions Soil Sci.. 1985;140:89.

5. Raju K.U.G., Atkinson G.. The thermodynamics of "scale" mineral solubilities. 3. Calcium sulfate in aqueous $\mathrm{NaCl}$ J. Chem. Eng. Data. 1990;35:361.

6. Porter E.T., Sanford L.P., Suttles S.E.. Gypsum dissolution is not a universal integrator of 'water motion' Limnol. Oceanogr.. 2000;45:145.

7. Liu S.T., Nancollas G.H.. The crystal growth of calcium sulfate dihydrate in the presence of additives J. Colloid Interf. Sci.. 1973;44:422. 
8. Mbogoro M.M., Snowden M.E., Edwards M.A., Peruffo M., Unwin P.R.. Intrisic kinetics of gypsum and calcium sulfate anhydrite dissolution: surface selective studies under hydrodynamic control and the effect of additives J. Phys. Chem. C. 2011;115:10147.

9. Fisher R.D., Mbogoro M.M., Snowden M.E., et al. Dissolution kinetics of polycrystalline calcium sulfate-based materials: influence of chemical modification ACS Appl. Mater. Interfaces. 2011;3:3528.

10. Hall C., Cullen D.. Scanning Force Microscopy of gypsum dissolution and crystal growth AIChE J.. 1996;42:232.

11. Bosbach D., Hochella M.F.. Gypsum growth in the presence of growth inhibitors: a scanning force microscopy study Chem. Geol.. 1996;132:227.

12. Colombani J.. Measurement of the pure dissolution rate constant of a mineral in water Geochim. Cosmochim. Acta. 2008;72:5634.

13. Pachon-Rodriguez E.A., Guillon E., Houvenaghel G., Colombani J.. Pressure solution as origin of the humid creep of a mineral material Phys. Rev. E. 2011;84:066121.

14. Chappuis J.. A model for a better understanding of the cohesion of hardened hydraulic materials Colloids Surf. A. $1999 ; 156: 223$.

15. Gartner E.M.. Cohesion and expansion in polycrystalline solids formed by hydration reactions - The case of gypsum plasters Cement Concrete Res.. 2009;39:289.

16. Sattler H.. Elastic and plastic deformations of plaster units under uniaxial compressive stress Mater. Struct.. $1974 ; 7: 159$.

17. Schott J., Pokrovsky O.S., Oelkers E.H.. The Link Between Mineral Dissolution/Precipitation Kinetics and Solution Chemistry Rev. Mineral. Geochem.. 2009;70:207.

18. Gautier JM, Oelkers EH, Schott J. Are quartz dissolution rates proportional to BET surface areas? Geochim. Cosmochim. Acta. 2001;65:1059.

19. Kaunisto E., Marucci M., Axelsson A.. Dissolution kinetics or pure mass transfer? A mechanistic study of dissolution AIChE J.. 2011;57:2610.

20. Colombani J., Bert J.. Holographic interferometry study of the dissolution and diffusion of gypsum in water Geochim. Cosmochim. Acta. 2007;71:1913.

21. Colombani J., Bert J.. Holographic convection visualization during thermotransport studies - Application to microgravity experiments Meas. Sci. Technol.. 1999;10:886.

22. Fan C.F., Teng H.H.. Surface behavior of gypsum during dissolution Chem. Geol.. 2007;245:242. 
23. Murphy W.M., Oelkers E.H., Lichtner P.C.. Surface reaction versus diffusion control of mineral dissolution and growth rates in geochemical processes Chem. Geol.. 1989;78:357.

24. Pachon-Rodriguez E.A., Piednoir A., Colombani J.. Pressure solution at the molecular scale Phys. Rev. Lett.. 2011;107:146102.

25. Jeschke A.A., Dreybrodt W.. Pitfalls in the determination of empirical disolution rate equations of minerals from experimental data and a way out: an iterative procedure to find valid rate equations, applied to Ca-carbonates and sulfates Chem. Geol.. 2002;192:183. 


\begin{tabular}{ccccc} 
Gypsum & $N$ & $\overline{\mathbf{k}}$ & $\sigma$ & $\Delta k$ \\
\hline Mazan (010) & 7 & $\mathbf{4 3}$ & 21 & 8 \\
Sig (010) & 2 & $\mathbf{6 9}$ & 22 & 22 \\
Tarascon (010) & 2 & $\mathbf{4 2}$ & 5 & 5 \\
Mateck (010) & 2 & $\mathbf{3 8}$ & 8 & 8 \\
All origins (010) & 13 & $\mathbf{4 6}$ & 19 & 6 \\
Tarascon (120) & 2 & $\mathbf{7 2}$ & 27 & 27
\end{tabular}

Table 1: Number of experiments $N$, average value $\bar{k}$, standard deviation $\sigma$ and standard error $\Delta k$, in $\mu \mathrm{mol} \mathrm{m}^{-2}$ $\mathrm{s}^{-1}$, of the pure dissolution rate constant of the (010) and (120) faces of single crystals of gypsum of various origins in pure water. 


\begin{tabular}{ccccc} 
Solution & $N$ & $\overline{\mathbf{k}}$ & $\sigma$ & $\Delta k$ \\
\hline Pure water & 13 & $\mathbf{4 6}$ & 19 & 6 \\
Tartaric-boric acid & 4 & $\mathbf{7 4}$ & 12 & 7 \\
Trilon & 3 & $\mathbf{2 1}$ & 7 & 5 \\
Sequion & 3 & $\mathbf{1 1}$ & 0.6 & 0.4 \\
Dequest & 5 & $\mathbf{8 . 0}$ & 1.2 & 0.6 \\
STMP & 12 & $\mathbf{3 . 3}$ & 1.1 & 0.3
\end{tabular}

Table 2: Number of experiments $N$, average value $\bar{k}$, standard deviation $\sigma$ and standard error $\Delta k$, in $\mu \mathrm{mol} \mathrm{m}^{-2}$ $\mathrm{s}^{-1}$, of the pure dissolution rate constant of the (010) face of a Mazan gypsum single crystal in water containing various additives. 


\section{List of Figures}

1 Digital holographic interferograms of the dissolution of a gypsum single crystal in water 10, 60, 120, 180 and 360 min. after the beginning of the experiment. The sample lies just below the bottom fringe. The dimensions of each interferogram is $5 \times 18 \mathrm{~mm}^{2} \ldots \ldots \ldots \ldots \ldots$

2 Evolution of the dissolved species concentration with vertical position for the holographic interferograms of the experiment in Figure 1. From bottom to top, the red, green, blue, pink and light blue dots correspond to the 5 consecutive elapsed times and the black curves are theoretical fits. The horizontal line is the solubility of gypsum in water. The crystal is situated at $z=0 \ldots \ldots 14$

3 Evolution of the pure dissolution rate constant of the cleavage plane of gypsum with the concentration of STMP in the aqueous solution where the crystal dissolves. The horizontal line is the value in pure

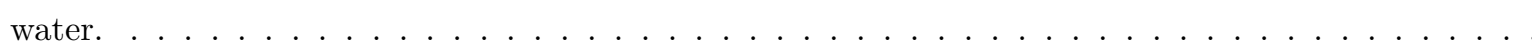

4 Pure dissolution rate constant of the (010) face of a Mazan gypsum single crystal in water containing

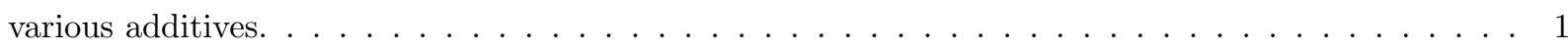



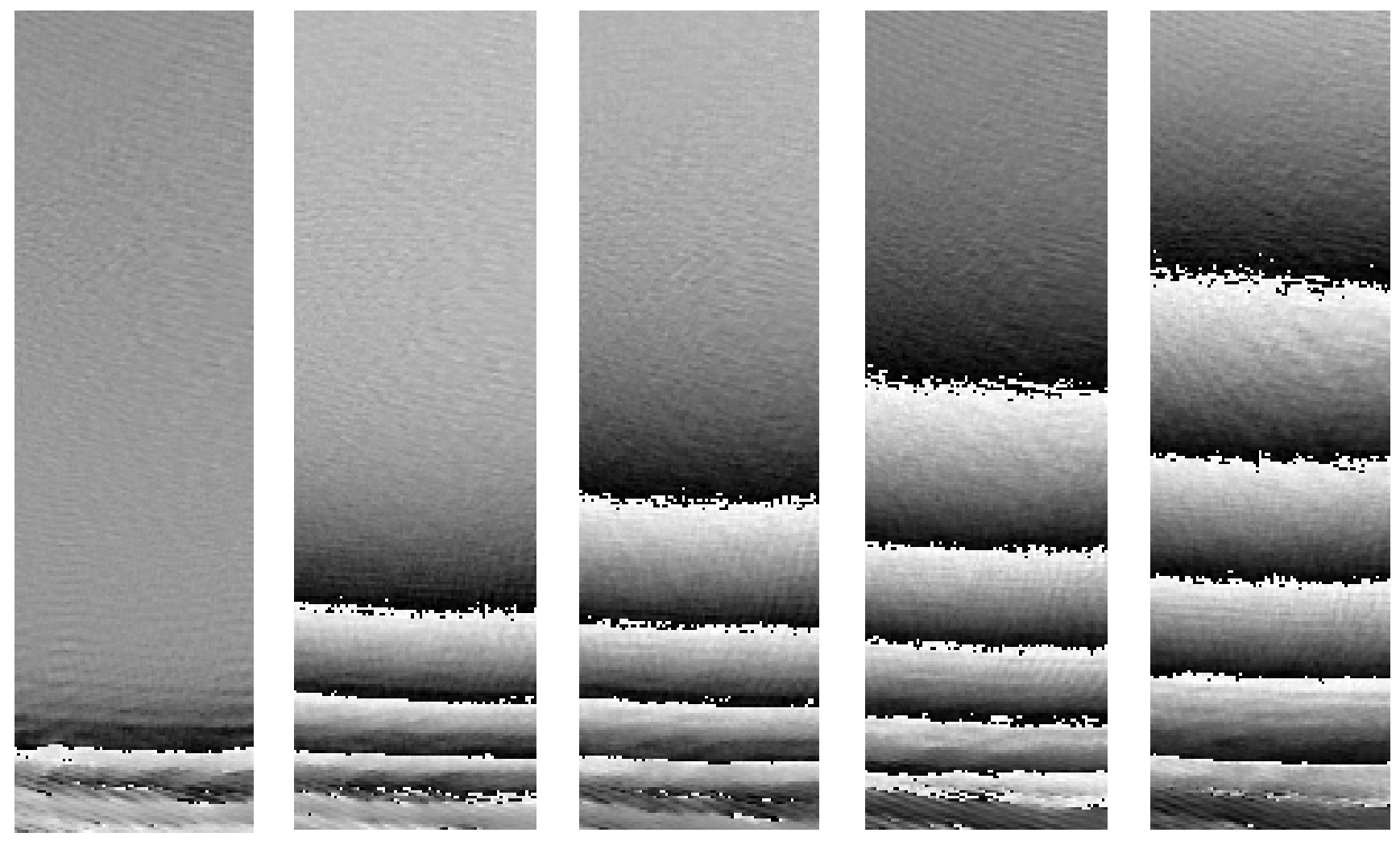

Figure 1: Digital holographic interferograms of the dissolution of a gypsum single crystal in water 10, 60, 120, 180 and $360 \mathrm{~min}$. after the beginning of the experiment. The sample lies just below the bottom fringe. The dimensions of each interferogram is $5 \times 18 \mathrm{~mm}^{2}$. 


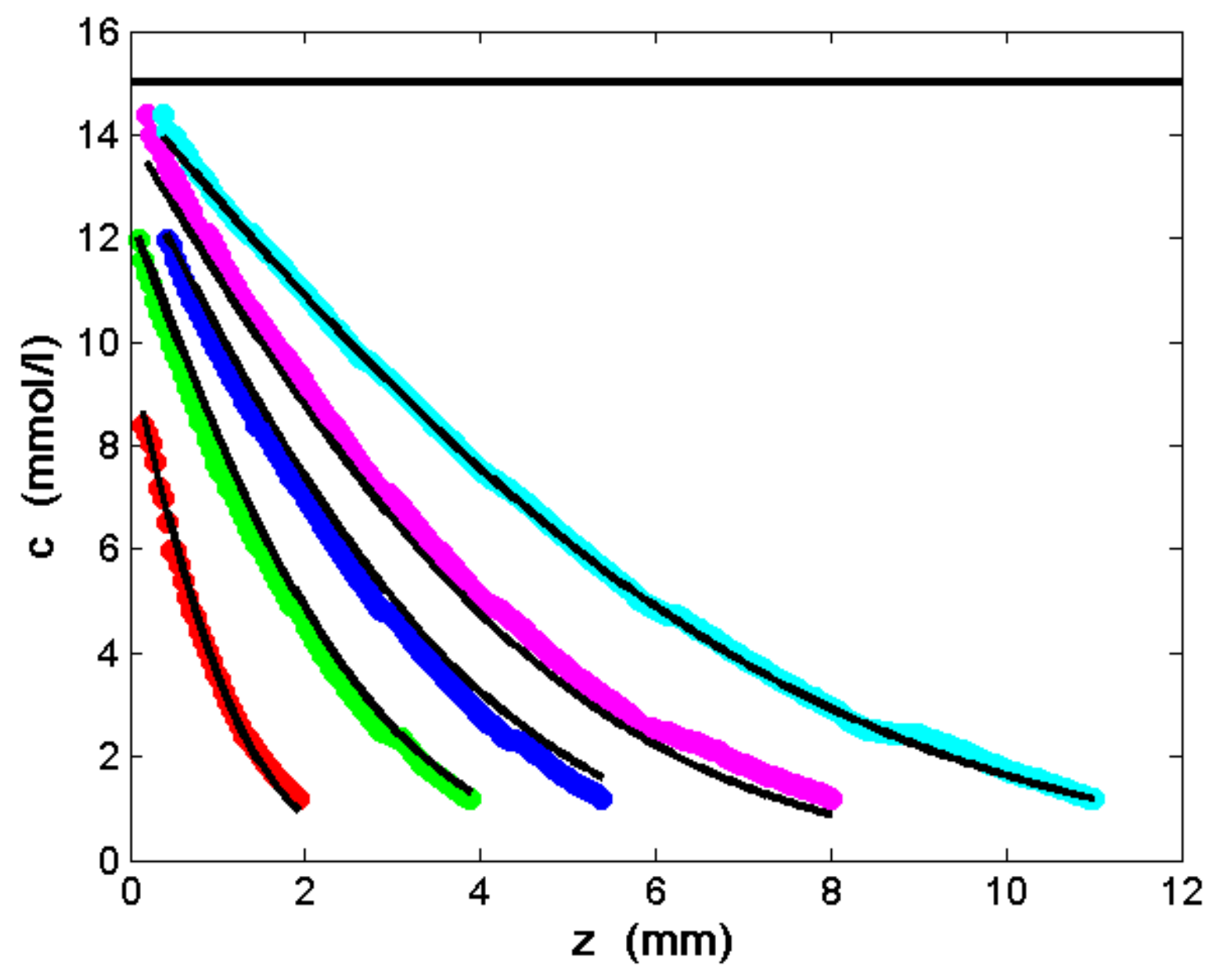

Figure 2: Evolution of the dissolved species concentration with vertical position for the holographic interferograms of the experiment in Figure 1. From bottom to top, the red, green, blue, pink and light blue dots correspond to the 5 consecutive elapsed times and the black curves are theoretical fits. The horizontal line is the solubility of gypsum in water. The crystal is situated at $z=0$. 


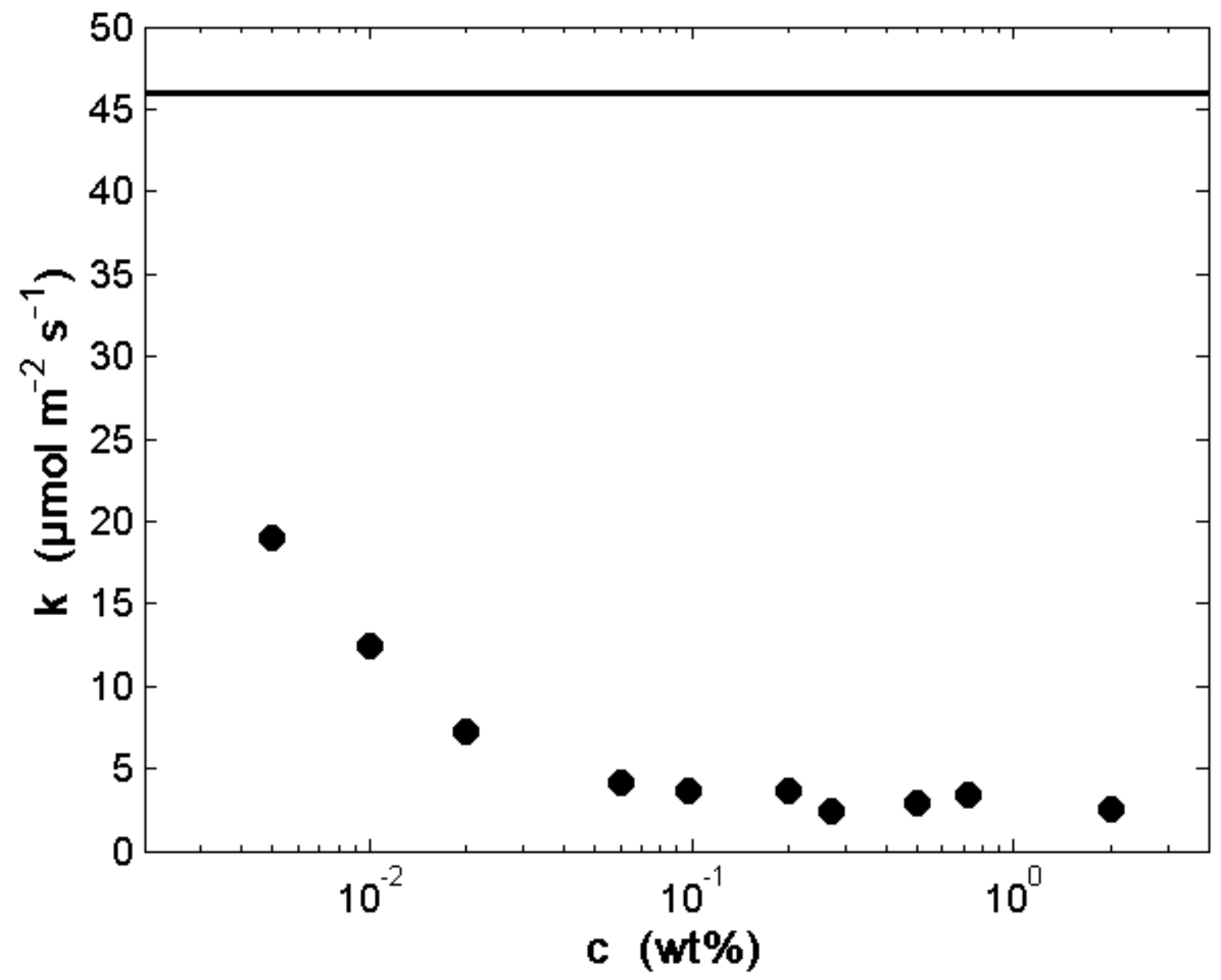

Figure 3: Evolution of the pure dissolution rate constant of the cleavage plane of gypsum with the concentration of STMP in the aqueous solution where the crystal dissolves. The horizontal line is the value in pure water. 


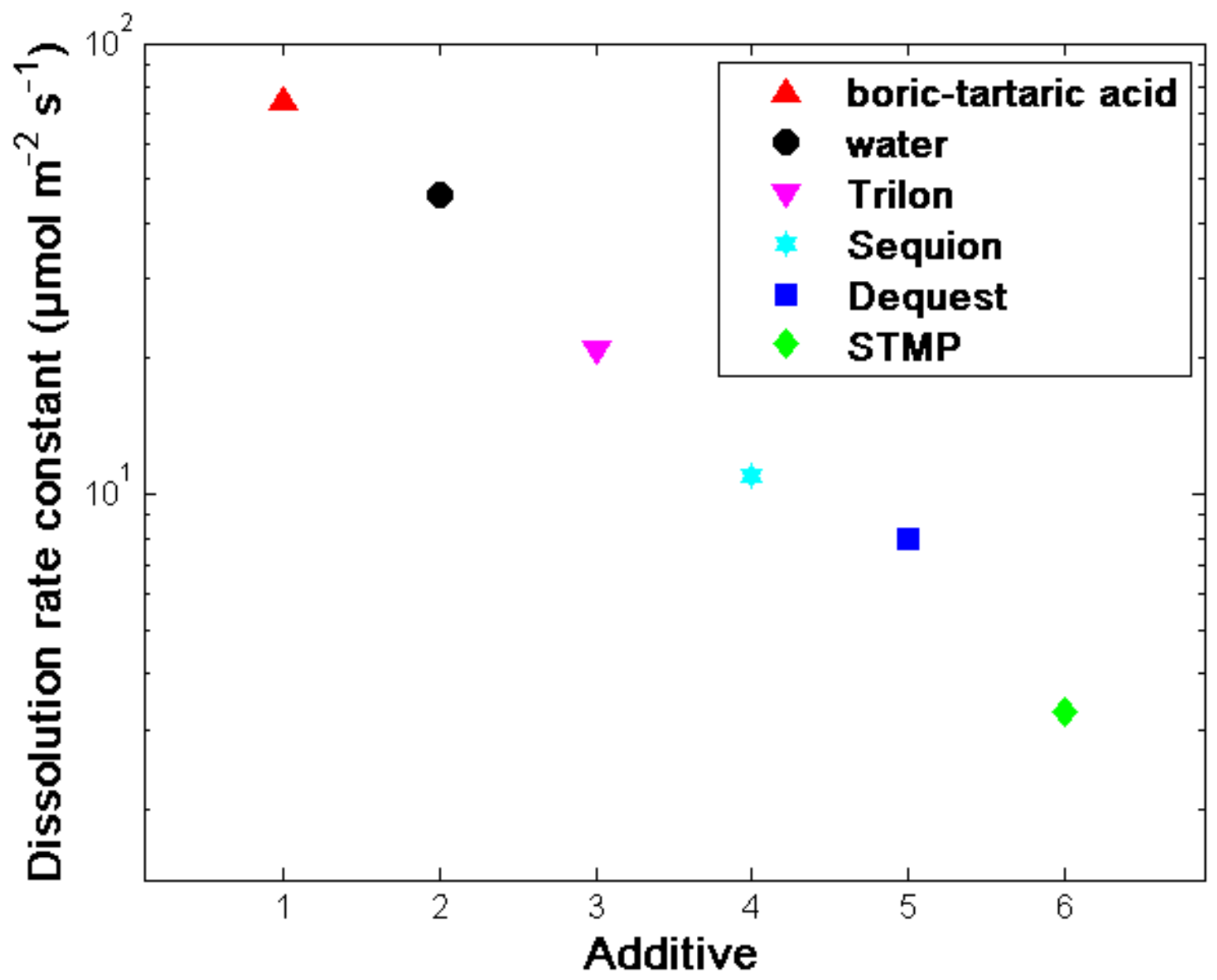

Figure 4: Pure dissolution rate constant of the (010) face of a Mazan gypsum single crystal in water containing various additives. 